\title{
Cardiovascular mortality in Dutch men during 1996 European football championship: longitudinal population study
}

\author{
Daniel R Witte, Michiel L Bots, Arno W Hoes, Diederick E Grobbee
}

\begin{abstract}
Julius Centre for General Practice and

Patient-Oriented Research, University Medical Centre Utrecht,

Huispostnummer D01.335, 3584 CX Utrecht,

Netherlands

Daniel R Witte PhD student

Michiel L Bots assistant professor of epidemiology

Arno W Hoes professor of clinical epidemiology Diederick E Grobbee professor of clinical epidemiology

Correspondence to: D E Grobbee D.E.Grobbee@jc. azu.nl
\end{abstract}

BMJ 2000;321:1552-4

\begin{abstract}
Objective To investigate whether an important football match increases stress to such an extent that it triggers acute myocardial infarction and stroke. Design Longitudinal study of mortality around 22 June 1996 (the day the Dutch football team was eliminated from the European football championship). Mortality on 22 June was compared with the five days before and after the match and in the same period in 1995 and 1997.

Setting Netherlands.

Subjects Dutch population aged 45 years or over in June 1996.

Main outcome measures All cause mortality and mortality due to coronary heart disease and stroke. Results Mortality from coronary heart disease and stroke was increased in men on the day of the match (relative risk 1.51, 95\% confidence interval 1.08 to 2.09). No clear rise in mortality was observed for women (1.11, 0.80 to 1.56). Among men, about 14 excess cardiovascular deaths occurred on the day of the match.
\end{abstract}

Conclusion Important sporting events may provoke a sufficient level of stress to trigger symptomatic cardiovascular disease. The difference between men and women requires further investigation.

\section{Introduction}

The role of trigger factors in acute vascular events such as myocardial infarction and stroke has received increased attention in recent years. Heavy physical work, unusual mental or emotional stress, recent heavy alcohol use, and overeating have been proposed as possible triggering factors for myocardial infarction and stroke. ${ }^{1-7}$ These factors probably act as the final

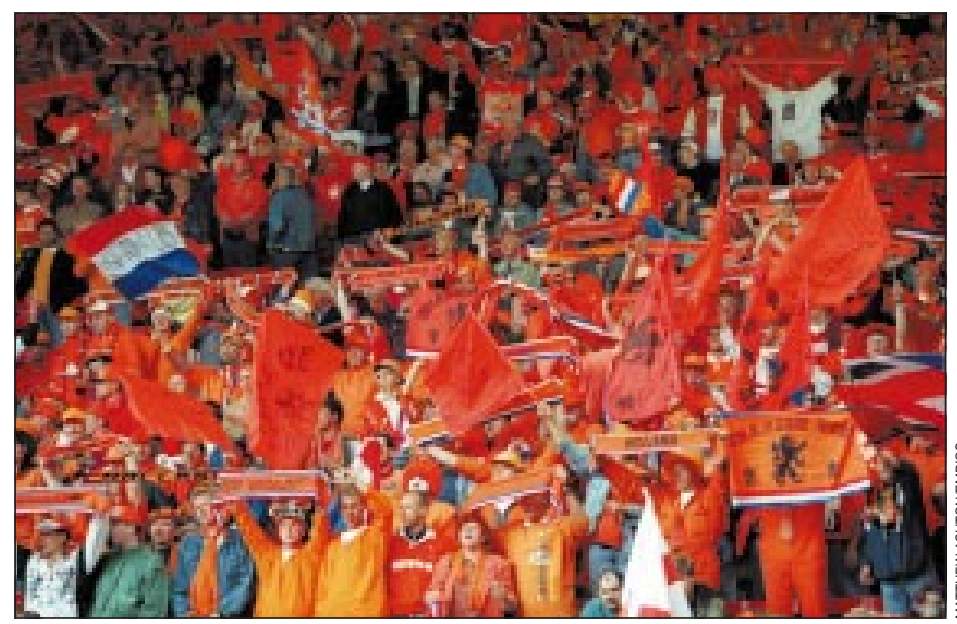

Was it the excitement, or was it the final score? The Netherlands-France match triggered excess cardiovascular events in Dutchmen-but not in women step in a sequence of events including the gradual development of atherosclerotic lesions.

A few reports have suggested that events that induce stress on large numbers of people in defined areas, such as earthquakes and war, may increase the incidence of fatal and non-fatal myocardial infarction at the population level..$^{8-13}$ We hypothesised that a situation which combines several of the proposed trigger factors at one point in time for a large population could lead to a sufficient number of cases to result in a detectable increase in national cardiovascular mortality. Notably, in a country like the Netherlands, an important football match of the national team could cause a combination of increased mental and emotional stress, alcohol intake, and possibly overeating and excessive smoking on a population level.

Between 8 June and 30 June 1996 the European football championship was played in England. The Netherlands advanced to the quarter finals and played France on 22 June. The match resulted in a nil-nil draw, even after extra time, and France won on penalty kicks. According to the ratings published by the Dutch broadcasting foundation, ${ }^{14}$ about 9.8 million people watched the match; this represents over $60 \%$ of the Dutch population of 15.5 million in 1996.

\section{Methods}

We analysed mortality data from the Dutch central bureau for statistics for June 1996, June 1995, and June 1997. The data comprised age and sex specific number of deaths, and deaths from acute myocardial infarction and stroke (ICD-10 codes I21, I22, and I60-I69).

We compared the number of deaths (all cause mortality and death from myocardial infarction or stroke) on the day of the football match (22 June 1996) with the mean number of deaths on the preceding and following five days, for men and women separately. Relative risks with $95 \%$ confidence intervals were calculated. In addition, we compared the data with those from corresponding periods in 1995 and 1997.

\section{Results}

The figure shows the number of deaths from all causes and myocardial infarction or stroke during 17-27 June 1996 for men and women separately. Mortality from all causes was increased in men on 22 June (173 v 150.1 cases; relative risk $1.15,95 \%$ confidence interval 0.98 to 1.35) and lower in women (146 v 164.1 cases; relative risk $0.89,0.75$ to 1.06 ). In men, mortality from myocardial infarction or stroke was significantly increased (relative risk 1.51, 1.08 to 2.09) on the day of the football match (41 cases) compared with the five days on either side (on average 27.2 cases). Mortality from myocardial infarction and stroke in men was lowest 
(21 cases) on the day after the match, but not below the lower bound of the $95 \%$ confidence interval.

In women, no clear difference in numbers of deaths from myocardial infarction and stroke was observed (38 v 34.1 cases; relative risk $1.11,0.8$ to 1.56 ). Analyses of the same periods in 1995 and 1997 showed no significant increases in cardiovascular mortality on 22 June compared with the respective previous and following five days.

\section{Discussion}

Mortality from acute myocardial infarction and stroke was increased in Dutch men on the day of an important football match compared with the preceding and following days. Compared with the average mortality in the preceding and following days, about 14 additional fatal events occurred; this is an increase of around $50 \%$. Our findings indicate that watching an important football match may be stressful. It further supports the view that the mental and other stressors of such an event may trigger acute myocardial infarction or stroke.

No corresponding increase in mortality occurred in women. This could mean that fewer women were exposed to the triggers (for example, because of less interest in football or lower alcohol consumption) or that they are less vulnerable to their effect. Less exposure seems the more likely explanation, although Tofler et al found that men were more likely to report triggers before myocardial infarction than women. ${ }^{1}$ The exact mechanism behind this difference is still unclear.

\section{Triggers}

The role of triggering factors has received increased attention since the recognition of a marked circadian, weekly, and seasonal variation in the occurrence of cardiovascular disease and most notably myocardial infarction, ${ }^{15-19}$ with clear peaks during morning hours, on Mondays, and in winter. A conceptual framework for the underlying pathophysiological mechanism for triggering both myocardial infarction and stroke has been proposed. ${ }^{23}$ The first step would be the transition of a non-vulnerable atherosclerotic plaque into a vulnerable state by unknown mechanisms. This would make the plaque susceptible to disruption by acute risk factors such as increased sympathetic nervous activity (leading to a surge in arterial pressure and vasoconstriction) and increased coagulability. A disrupted plaque could then provide a thrombogenic stimulus, at which point triggers causing further vasoconstriction or increased coagulability could aggravate the situation, eventually leading to embolisation, occlusion, and infarction.

For acute myocardial infarction and stroke, the lowest mortality was found on the day after the match, although this difference was not significant. Stress induced by the football match possibly resulted in an acceleration of mortality - that is, vulnerable men had their fatal myocardial infarction or stroke a day earlier than they would have otherwise.

The proposed acute risk factors could result from activities or situations that occur frequently in daily life: emotional upset or mental stress, ${ }^{12517}$ physical activity, ${ }^{1}{ }^{17}$ lack of sleep, ${ }^{1}$ overeating, ${ }^{1}$ heavy alcohol ingestion or smoking, ${ }^{14719}$ and sexual activity. ${ }^{120}{ }^{21}$ The
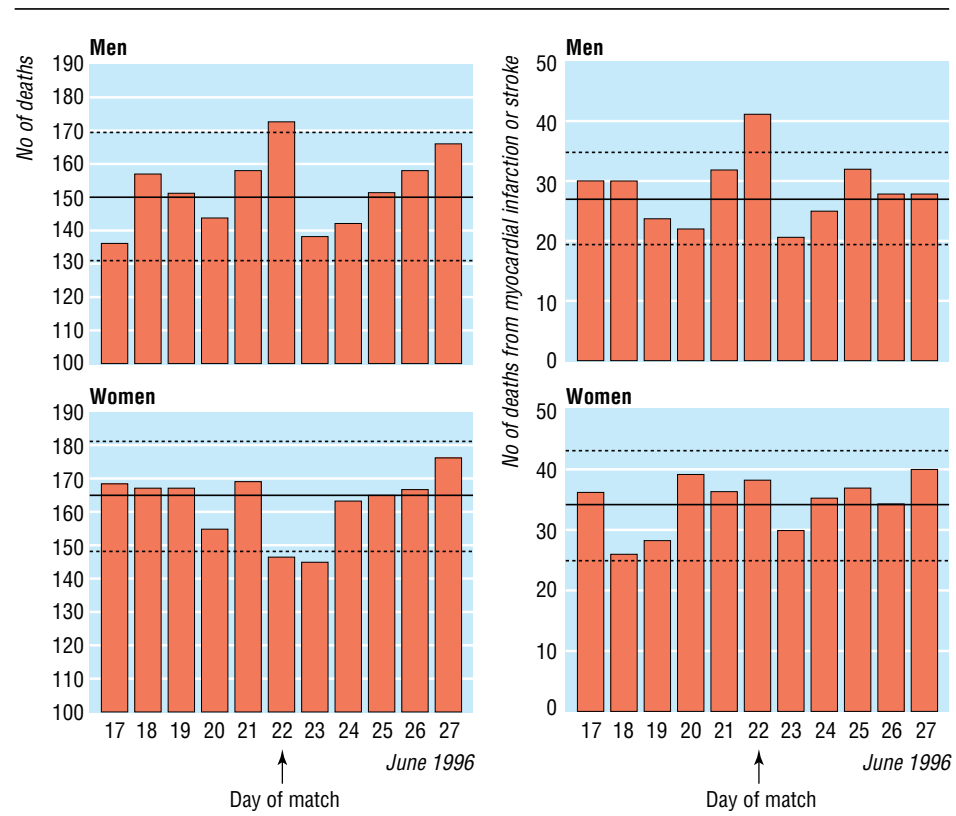

Numbers of deaths from all causes and from myocardial infarction or stroke in men and women aged $\geqslant 45$ years, 17 June-27 June 1996. The quarter final match of the European championship between Netherlands and France was played on 22 June. Horizontal lines represent the mean and $95 \%$ confidence intervals for the five days preceding and five days after 22 June

role of emotional or mental stress, physical activity, and heavy alcohol ingestion has been established mainly by retrospective questioning of people who have had non-fatal cardiovascular events. The finding of increased risks of cardiovascular events during earthquakes and wars ${ }^{8-13}$ has provided strong support for a triggering role of emotional and mental stress. Our findings show that an important football match can similarly provide sufficient triggers to cause a rise in mortality from myocardial infarction and stroke.

\section{Validity}

The role of national vital statistics in studies on causes of mortality has been disputed because of the limited validity and accuracy of these routinely collected data. It is, however, unlikely that changes in coding behaviour over days can explain our finding. Furthermore, all cause

\section{What is already known on this topic}

Factors such as heavy physical exercise, unusual mental or emotional stress, and high alcohol consumption have been proposed as trigger factors for myocardial infarction and stroke

Events that induce stress on a large number of people in a defined area, such as earthquakes and war, have been reported to increase the incidence of fatal and non-fatal myocardial infarction

\section{What this study adds}

Male mortality from myocardial infarction and stroke was increased on the day of an important football match of the Dutch national team, probably because of increased stress

Mortality in women was unaffected

The effect of a single match is detectable in national mortality data 
mortality showed the same trends as mortality from myocardial infarction and stroke.

\section{Implications}

Our results add prospective evidence for the role of triggering factors, including mental and emotional stress, in cardiovascular deaths in men. We also observed a clear sex difference that merits further investigation. The triggers induced by a critical football match may not be due solely to mental or emotional stress. Notably, heavy alcohol use, overeating, and excessive smoking may also play a part.

The role of trigger factors in cardiovascular disease illustrates that prevention of cardiovascular events goes beyond management of risk factors for atherosclerosis. Increased awareness of the impact of stressors in vulnerable subjects seems crucial. In addition, aspirin or $\beta$ blockers may prevent acute cardiovascular events being triggered in high risk subjects. ${ }^{22}{ }^{23}$

We thank the Dutch central bureau for statistics for providing the mortality data.

Contributors: DRW performed the data analysis and literature review and wrote the report. MLB participated in the data analysis, interpretation, and writing of the paper. AWH and DEG proposed the idea of the study. AWH participated in the design of the study, data analysis, and editing of the paper. DEG acquired the data and supervised the analysis and writing. He is the study guarantor.

Funding: None.

Competing interests: None declared.

1 Tofler GH, Stone PH, Maclure M, Edelman E, Davis VG, Robertson T, et al. Analysis of possible triggers of acute myocardial infarction (the MILIS study). Am J Cardiol 1990;66:22-7.

2 Willich SN, Maclure M, Mittleman M, Arntz HR, Muller JE. Sudden cardiac death. Support for a role of triggering in causation. Circulation 1993:87:1442-50.

3 Muller JE, Abela GS, Nesto RW, Tofler GH. Triggers, acute risk factors and vulnerable plaques: the lexicon of a new frontier. $J$ Am Coll Cardiol 1994;23:809-13

4 Hillbom M, Haapaniemi H, Juvela S, Palomaki H, Numminen H, Kaste M. Recent alcohol consumption, cigarette smoking, and cerebral infarction in young adults. Stroke 1995; $26: 40-5$.

5 Mittleman MA, Maclure M, Sherwood JB, Mulry RP, Tofler GH, Jacobs SC, et al. Triggering of acute myocardial infarction onset by episodes of anger. Determinants of myocardial infarction onset study investigators. Circulation 1995;92:1720-5.

6 Haapaniemi H, Hillbom M, Juvela S. Weekend and holiday increase in the onset of ischemic stroke in young women. Stroke 1996:27:1023-7.

7 Kauhanen J, Kaplan GA, Goldberg DE, Salonen JT. Beer binging and mortality: results from the Kuopio ischaemic heart disease risk factor study, a prospective population based study. BMJ 1997;315:846-51.

8 Trichopoulos D, Katsouyanni K, Zavitsanos X, Tzonou A, Dalla-Vorgia P. Psychological stress and fatal heart attack: the Athens (1981) earthquake natural experiment. Lancet 1983;i:441-4.

9 Meisel SR, Kutz I, Dayan KI, Pauzner H, Chetboun I, Arbel Y, et al. Effect of Iraqi missile war on incidence of acute myocardial infarction and sudden death in Israeli civilians. Lancet 1991;338:660-1.

10 Bergovec M, Mihatov S, Prpic H, Rogan S, Batarelo V, Sjerobabski V. Acute myocardial infarction among civilians in Zagreb city area. Lancet 1992:339:303.

11 Suzuki S, Sakamoto S, Miki T, Matsuo T. Hanshin-Awaji earthquake and acute myocardial infarction. Lancet 1995;345:981.

12 Leor J, Kloner RA. The Northridge earthquake as a trigger for acute myocardial infarction. Am J Cardiol 1996;77:1230-2.

13 Brown DL. Disparate effects of the 1989 Loma Prieta and 1994 Northridge earthquakes on hospital admissions for acute myocardial infarction: importance of superimposition of triggers. Am Heart J 1999:137:830-6.

14 NOS, kijk en luisteronderzoek. Maandoverzicht kijk-en luisteronderzoek televisie [Monthly overview of television ratings]. Hilversum: NOS, June 1996.

15 Willich SN. Epidemiologic studies demonstrating increased morning incidence of sudden cardiac death. Am J Cardiol 1990;66:15-7G.

16 Wroe SJ, Sandercock P, Bamford J, Dennis M, SlatteryJ, Warlow C. Diurnal variation in incidence of stroke: Oxfordshire community stroke project. $B M J$ 1992;304:155-8

17 Behar S, Halabi M, Reicher-Reiss H, Zion M, Kaplinsky E, Mandelzweig L, et al. Circadian variation and possible external triggers of onset of myocardial infarction. SPRINT Study Group. Am J Med 1993;94:395-400 duplicates

18 Spencer FA, Goldberg RJ, Becker RC, Gore JM. Seasonal distribution of acute myocardial infarction in the second National Registry of Myocardial Infarction. J Am Coll Cardiol 1998;31:1226-33.

19 Evans C, Chalmers J, Capewell S, Redpath A, Finlayson A, Boyd J, et al. "I don't like Mondays"-day of the week of coronary heart disease deaths in Scotland: study of routinely collected data. BMJ 2000;320:218-9.

20 Muller JE, Mittleman A, Maclure M, Sherwood JB, Tofler GH. Triggering myocardial infarction by sexual activity. Low absolute risk and prevention by regular physical exertion. Determinants of Myocardial Infarction Onset Study Investigators. JAMA 1996;275:1405-9.

21 Muller JE. Sexual activity as a trigger for cardiovascular events: what is the risk? Am J Cardiol 1999.84.2N-5N

22 Willich SN, Linderer T, Wegscheider K, Leizorovicz A, Alamercery I, Schröder R, et al. Increased morning incidence of myocardial infarction in the ISAM study: absence with prior $\beta$-adrenergic blockade. Circulation $1989 ; 80: 853-8$.

23 Ridker PM, Manson JE, Buring JE, Muller JE, Hennekens CH. Circadian variation of acute myocardial infarction and the effect of low-dose aspirin in a randomized trial of physicians. Circulation 1990;82:897-902.

\section{Streptokinase versus alteplase and other treatments for acute and delayed thrombolysis of blood stains in clothing}

C K Pager

Royal Prince Alfred

Hospital, Sydney,

Australia 2050

C K Pager

resident medical officer

ckpager@

bigfoot.com

BMJ 2000;321:1554-6

\section{Abstract}

Objective To assess the usefulness of heparin, alteplase, and streptokinase in removing blood stains. Design Randomised controlled trial.

Setting Hospital laundry.

Interventions Blood stains were allocated to treatment with alteplase, streptokinase, heparin, a commercial enzymatic stain remover, or no treatment at all after three or seven hours and then washed in hot or cold water two hours later.

Results Both hot water and early treatment were strongly associated with improved stain removal. All four treatments were associated with a worse outcome than no treatment at all, although for streptokinase this trend did not reach significance. The commercial stain remover gave the worst results of all treatments tested.
Conclusions Contrary to popular wisdom, hot water is much more effective than cold in removing blood stains. Methodologically rigorous research and evidence based principles are needed within the laundry industry, and the role of thrombolytic drugs should be assessed further.

\section{Introduction}

Thrombolytic drugs are used for a widening and often controversial array of indications, including myocardial infarction, ischaemic stroke, and massive pulmonary embolism. ${ }^{1-3}$ However, little attention has been given to their role in treating blood stains in clothing, an event that causes appreciable morbidity to the affected medical officer. 